\title{
VIABILIDADE DE PÓLEN IN VIVO E IN VITRO EM GENÓTIPOS DE AÇAIZEIRO
}

\author{
Maria do Socorro Padilha de Oliveira ${ }^{1}$ \\ Márcia Motta Maués ${ }^{2}$ \\ Maura Anjos de Andrade Kalume ${ }^{3}$
}

\section{Recebido em 17/8/1999. Aceito em 14/4/2000}

\begin{abstract}
RESUMO - (Viabilidade de pólen in vivo e in vitro em genótipos de açaizeiro). Determinou-se a viabilidade de pólen in vivo e in vitro em 20 genótipos de açaizeiro, da coleção de germoplasma da Embrapa Amazônia Oriental. Os grãos de pólen in vivo foram retirados de botão floral (BF) e de flor recém-aberta (FA) e os in vitro de ampolas armazenadas em freezer $\left(-10^{\circ} \mathrm{C}\right)$, com período de armazenamento (PA) de um (PA1), três (PA3), seis (PA6) e doze (PA12) meses. Utilizou-se a solução de Baker, sendo foi retirada uma amostra para cada estádio. Calculou-se a taxa de viabilidade pela contagem de, aproximadamente, 500 grãos de pólen. Pólen in vivo, na maioria dos genótipos exibiram alta viabilidade com médias de $84,8 \%$ para botões e $93,2 \%$ para flores recém-abertas, sendo as melhores taxas registradas nos genótipos 3 e 19. Para pólen in vitro, os genótipos apresentaram redução na viabilidade com o aumento do período de armazenamento (PA1: 79,6\%, PA3: 77,4\%, PA6: 74,1\% e PA12: 61,3\%) mas o armazenamento não foi prejudicial, pois grande parte dos genótipos alcançaram valores acima de 50\%, destacandose os genótipos 3 e 9 com as maiores percentagens. Portanto, pode-se considerar que, nos genótipos testados, pólen in vivo têm alta viabilidade e os in vitro devem ser usados em polinizações controladas sem prejuízos na fecundação, em até doze meses de conservação.
\end{abstract}

Palavras-chave - Euterpe oleracea, Arecaceae, Melhoramento, conservação, pólen fresco, pólen armazenado

ABSTRACT - (In vivo and in vitro pollen viability of açaí palm genotypes). The rate of in vivo and in vitro pollen viability, in 20 açai palm (Euterpe oleracea Mart.) genotypes, belonging to the germplasm collection of Embrapa Eastern Amazon, was determined. The in vivo pollen grains were extracted from floral buds (FB) and recently opened flowers (ROF). The in vitro pollen grains were obtained from flasks stored in the freezer under $-10^{\circ} \mathrm{C}$, with storage period (SP) of one (SP1), three (SP3), six (SP6) and twelve (SP12) months of storage. The pollen viability was accessed utilizing the Baker's procedure. The viability rate was achieved by counting up to 500 grains per slide. Most of the genotypes showed high viability for in vivo pollen, with an average of $84.8 \%$ in the BF samples and $93.2 \%$ in the ROF samples. For the in vitro pollen, a decrease in the viability in relation to the storage period was observed (SP1: 79.6\%, SP3: 77.4\%, SP6: 74.1\% and SP12: 61.3\%). Nevertheless, this decrease was not hazardous, observing that most of the genotypes achieved rates over $50 \%$ of viability, particularly the genotypes 3 and 9 , which presented the major percentages. Therefore, all the tested genotypes presented high viability for in vivo pollen, and the in vitro pollen can be used for controlled pollination without any fecundity injury up to one year of storage.

Key words - Euterpe oleracea, Arecaceae, Breeding, Conservation, Stored pollen, Pollen viability

1 Eng. Agro., MSc., Embrapa Amazônia oriental, C. Postal 48, Belém, PA, CEP 55095-100, spadilha@ cpatu.embrapa.br

2 Bióloga, MSc., Embrapa Amazônia oriental, C. Postal 48, CEP 66095-100, marcia@cpatu.embrapa.br

3 Eng. Agro., Aluna do curso de Mestrado em Biologia Vegetal da Faculdade de Ciências Agrárias do Pará 


\section{Introdução}

O açaizeiro (Euterpe oleracea Mart.) é uma palmeira nativa da Amazônia que ocorre em grandes concentrações no Pará, principalmente no Estuário Amazônico, onde encontra-se em estado selvagem (Cavalcante 1991).

Destaca-se como produtor de frutos e palmito mas, grande parte dessas produções, ainda, provém do extrativismo, não garantindo produtos de qualidade e nem produções contínuas, havendo necessidade de serem desenvolvidos estudos que viabilizem seu cultivo. A expansão do mercado de frutos vem estimulando muitos agricultores no plantio comercial do açaizeiro, os quais têm encontrado barreiras na escolha de sementes, devido a ausência de sementes melhoradas que possam garantir maiores produtividades e qualidades nos produtos obtidos e, consequentemente lucros certos aos produtores.

Na tentativa de solucionar este problema, a Embrapa Amazônia Oriental instalou uma coleção de germoplasma de açaí e vem realizando várias pesquisas com vista a subsidiar programas de melhoramento, dentre as quais a polinização controlada. Nesse aspecto, tem-se como relevante o conhecimento da viabilidade do pólen dos genótipos existentes.

A viabilidade do pólen pode ser determinada através de um grande número de técnicas (Dafni 1992; Kearns \& Inouye 1993). É considerada uma medida de fertilidade masculina muito empregada no monitoramento de pólen armazenado, de modo a garantir a fecundação, tornando possíveis cruzamentos entre genótipos de potencial econômico que apresentam floração em épocas distintas (Kearns \& Inouye 1993; Miranda 1993).

Na literatura disponível, há apenas um trabalho que aborda superficialmente sobre a viabilidade de pólen no açaizeiro, sendo considerada pelos autores como de alta percentagem (Bovi et al. 1988). Em outras palmeiras, este estudo tem recebido atenção especial, devido a produção de híbridos, sendo realizado em grãos de pólen frescos e conservados sob baixas temperaturas (Whitehead 1966; Rognon \& Nucé de Lamothe 1978; Akihama et al. 1979; Arnaud 1980; Ekaratne \& Senathirajah 1983; Miranda 1986; Bovi et al. 1988).

Assim, na tentativa de obter subsídios para programas de melhoramento do açaizeiro, este trabalho teve como objetivo determinar a taxa de viabilidade de grãos de pólen in vivo e in vitro em genótipos dessa palmeira existentes na coleção de germoplasma da Embrapa Amazônia Oriental, em Belém, Pará.

\section{Material e métodos}

Para a realização desse estudo, foram selecionados ao acaso, na coleção de germoplasma de açaí da Embrapa Amazônia oriental, localizada em Belém, PA ( $\left.1^{\circ} 27^{\prime} \mathrm{S} 48^{\circ} 29^{\prime} \mathrm{W}\right), 20$ genótipos com aproximadamente treze anos de idade, em plena fase reprodutiva.

O tipo climático de Belém, segue o padrão Afi, segundo classificação de Köppen, caracterizado por apresentar temperatura média anual de $25,9^{\circ} \mathrm{C}$, umidade relativa do ar média de $84 \%$ e precipitação pluviométrica de $2.900 \mathrm{~mm} /$ ano.

Em cada indivíduo foi marcada uma inflorescência próxima a maturação e, no momento da exposição do cacho, foi retirada uma parte das ráquilas, sendo levada ao laboratório para beneficiamento do pólen. O pólen obtido foi acondicionado em ampolas com rótulos de identificação, para conservação em baixa temperatura (freezer, $-10^{\circ} \mathrm{C}$ ). Outra parte da inflorescência ficou na planta para completar o ciclo de floração e, permitir a coleta de grãos de pólen in vivo.

Na ocasião da plena fase de floração masculina, coletou-se uma ráquila/inflorescência, entre 8 e 9 horas da manhã, e retirou-se dois estádios florais: botão floral em pré-antese (BF) e flor aberta (FA) para determinação da viabilidade do pólen in vivo, através da solução de Baker (Dafni 1992). Para tanto, retirou-se uma amostra (duas anteras) de cada estádio, sendo 
macerada em lâmina identificada, acrescentando-se uma gota desta solução, homogeneizandoa, colocando-a em uma câmara úmida (placa de Petri com papel umedecido) e, em seguida, dentro de uma incubadora biológica por 25 a 30 minutos em temperatura de $37 \pm 3^{\circ} \mathrm{C}$.

Dos grãos de pólen armazenados (in vitro), foi retirada uma amostra por período, durante quatro períodos de armazenamento (PA): um (PA1), três (PA3), seis (PA6) e doze (PA12) meses de conservação, sendo colocada para hidratar por duas horas, em câmara úmida e, após a hidratação seguiu-se a mesma metodologia aplicada para pólen in vivo.

Pelo fato de, nessa técnica, o corante reagir onde há plena atividade enzimática, indicada pela presença da esterase localizando tecido vivo, considerou-se como grãos de pólen viáveis aqueles corados de azul e como não viáveis os incolores.

Com os dados obtidos em cada genótipo, calculou-se a percentagem de pólen viáveis, sendo realizada através da contagem de grãos de pólen viáveis e inviáveis existentes em cada lâmina para pólen in vivo nos dois estádios florais (BF e FA) e in vitro, para os quatro períodos (PA1, PA3, PA6 e PA12), totalizando 500 grãos/ lâmina, sendo usada para o cálculo da percentagem a seguinte fórmula:

Viabilidade do pólen $(\%)=\mathrm{N}$. de grãos corados/ N. de grãos contados .100

\section{Resultados e discussão}

As taxas de viabilidade do pólen in vivo e in vitro, obtidas nos 20 genótipos de açaizeiro estudados, encontram-se nas Tab. 1 e 2.

Para pólen in vivo, os genótipos mostraram viabilidade alta, tanto em botões florais como em flores recém-abertas, com médias de 84,8\% e $93,2 \%$, respectivamente, atingindo no segundo estádio valor próximo a $100 \%$ (Tab. 1). Tais resultados foram superiores aos obtidos por Bovi et al. (1988), quando avaliaram açaizeiros e outras espécies de estipe único e múltiplo perten-
Tabela 1. Viabilidade para pólen in vivo, em dois estádios florais: botões florais (BF) e flores recém-abertas (FA), obtidas em 20 genótipos de açaizeiro, pertencentes a coleção de germoplasma da Embrapa Amazônia Oriental, Belém-PA, 1998.

\begin{tabular}{ccc}
\hline \multirow{2}{*}{ Genótipos } & Viabilidade de pólen $(\%) /$ estádios florais \\
\cline { 2 - 3 } & Botão floral & Flor aberta \\
\hline 1 & 87,7 & 93,6 \\
2 & 85,9 & 90,8 \\
3 & 94,8 & 98,0 \\
4 & 86,9 & 88,1 \\
5 & 80,0 & 92,2 \\
6 & 87,4 & 91,9 \\
7 & 76,3 & 93,0 \\
8 & 89,4 & 96,5 \\
9 & 90,8 & 93,6 \\
10 & 87,6 & 95,0 \\
11 & 89,6 & 96,2 \\
12 & 82,2 & 94,6 \\
13 & 73,6 & 87,3 \\
14 & 82,1 & 95,1 \\
15 & 75,9 & 90,0 \\
16 & 74,7 & 85,6 \\
17 & 78,5 & 95,2 \\
18 & 88,1 & 92,4 \\
19 & 94,8 & 98,3 \\
20 & 89,6 & 96,2 \\
Média & 84,8 & 93,2 \\
Cv (\%) & 8,0 & 4,0 \\
\hline
\end{tabular}

centes ao gênero Euterpe, nas condições climáticas de Ubatuba, no litoral do estado de São Paulo, cujos valores variaram de 76 a $89 \%$.

Vale mencionar que, no trabalho em questão, a coleta dos estádios florais foi realizada durante a fase masculina, porém no horário entre 8 e 9 horas quando as anteras começam a abrir, levando a crer que a viabilidade deva atingir sua plenitude na ocasião da antese máxima, momento em que ocorre a abertura total da anteras, existindo maior disponibilidade de pólen (entre 10h30 e 12h30), ou logo após a antese, como relatam Kearns \& Inouye (1993) para a maioria das espécies. Na Fig. 1, encontra-se o detalhe de pólen viável (corado) e inviável (não corado) em botões florais e flores recém-abertas.

A variação entre o percentual de viabilidade de pólen in vivo, nos genótipos, foi conside- 


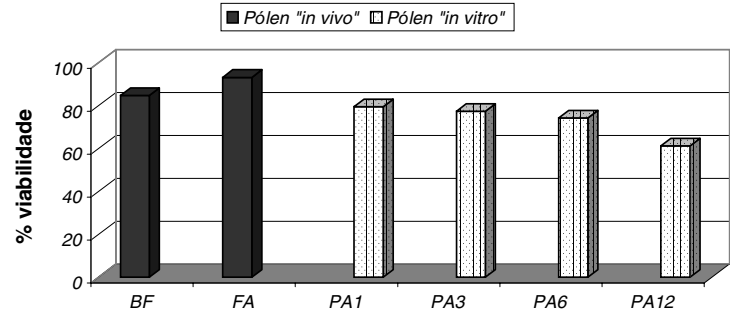

Figura 1. Viabilidades médias para grãos de pólen in vivo, em dois estádios florais, botão floral (BF) e flor aberta (FA) e in vitro, em quatro períodos de armazenagem (PA1, PA2, PA6 e PA12), obtidas em açaizeiros da coleção de germoplasma da Embrapa Amazônia Oriental, Belém-PA, 1998.

rada baixa para os dois estádios, 8,04 e 4,04\% respectivamente, fornecendo indícios de que os genótipos não diferem entre si ou que esta característica seja pouco influenciada pelo ambiente.

Em relação ao botão floral, o genótipo que exibiu a percentagem mais baixa foi o $13 \mathrm{com}$ $73,6 \%$, enquanto a mais alta foi registrada nos genótipos 3 e 19 (94,8\%). No caso de flores recém-abertas, apesar de todos terem atingido alta viabilidade, o destaque ficou com o genótipo 19 que apresentou $98,3 \%$, ficando o menor valor com o genótipo 16 que alcançou $85,6 \%$ de grãos de pólen viáveis. Pelo fato do genótipo 19 ter atingido a maior viabilidade para pólen in vivo, pode-se considerar como um bom indicativo para que seja usado em programas de melhoramento. Contudo, os demais genótipos também podem ser úteis, pois apresentaram percentagens significativas.

No que diz respeito a viabilidade de pólen in vitro, avaliada nos quatro períodos de armazenagem (um, três, seis e doze meses), pode-se verificar que houve uma redução com o aumento do tempo de conservação (Tab. 2) mas, esta diminuição não foi drástica. Detalhe dos grãos de pólen viáveis e inviáveis em cada período encontra-se na Fig. 2. Para um mês, a percentagem média foi de $79,6 \%$, enquanto nos demais períodos as taxas caíram para $77,4 \%, 74,1 \%$ e $61,3 \%$, respectivamente. Entretanto, apresentaram percentagens menores que as obtidas para
Tabela 2. Viabilidade para pólen in vitro, em quatro períodos de armazenamento: um, três, seis e doze meses, obtidas em 20 genótipos de açaizeiro, pertencentes a coleção de germoplasma da Embrapa Amazônia Oriental, BelémPA, 1998.

\begin{tabular}{crrrc}
\hline Genótipos & \multicolumn{4}{c}{ Viabilidade de pólen $(\%) /$} \\
& \multicolumn{4}{c}{ Períodos de armazenamento } \\
\cline { 2 - 5 } & 1 mês & 3 meses & 6 meses & 12 meses \\
\hline 1 & 79,3 & 76,5 & 72,1 & 59,6 \\
2 & 83,0 & 80,4 & 77,3 & 66,3 \\
3 & 90,2 & 88,0 & 85,6 & 63,1 \\
4 & 84,8 & 81,5 & 77,9 & 65,8 \\
5 & 69,1 & 65,2 & 63,4 & 49,4 \\
6 & 81,5 & 79,3 & 75,3 & 61,2 \\
7 & 74,7 & 72,1 & 69,4 & 57,8 \\
8 & 85,2 & 83,1 & 80,2 & 68,9 \\
9 & 88,3 & 86,7 & 85,6 & 74,5 \\
10 & 86,2 & 84,6 & 80,1 & 67,6 \\
11 & 85,0 & 81,2 & 77,3 & 65,0 \\
12 & 78,0 & 75,4 & 70,0 & 58,1 \\
13 & 71,7 & 70,5 & 68,9 & 55,4 \\
14 & 80,3 & 78,6 & 75,7 & 63,2 \\
15 & 74,1 & 73,8 & 70,2 & 59,0 \\
16 & 74,0 & 72,0 & 70,5 & 57,6 \\
17 & 75,5 & 73,7 & 69,3 & 57,3 \\
18 & 75,2 & 74,5 & 72,4 & 60,1 \\
19 & 84,8 & 82,0 & 80,3 & 67,6 \\
20 & 70,3 & 68,9 & 65,1 & 48,9 \\
Média & 79,6 & 77,4 & 74,1 & 61,3 \\
CV (\%) & 8,3 & 8,6 & 9,0 & 11,5 \\
\hline
\end{tabular}

pólen in vivo (Fig. 3). Resultados semelhantes foram obtidos em pólen armazenado de outras palmeiras (Ekaratne \& Senathirajah 1983 e Miranda 1986). Porém, Rognon \& Nucé de Lamothe (1978) encontraram 40\% de viabilidade para pólen armazenado de coqueiro.

Bérnard \& Noiret (1970) ressaltam que pólen com pelo menos $60 \%$ de viabilidade podem ser considerados como bem conservados, enquanto para Arnaud (1979) só podem ser armazenados grãos de pólen que possuam viabilidades iniciais superiores a $70 \%$, devendo ser descartados os que atingirem taxas inferiores a $40 \%$. Como os resultados aqui encontrados foram superiores a este valor, acredita-se que os grãos de pólen de açaizeiro armazenados até doze meses poderão ser aplicados com sucesso em 


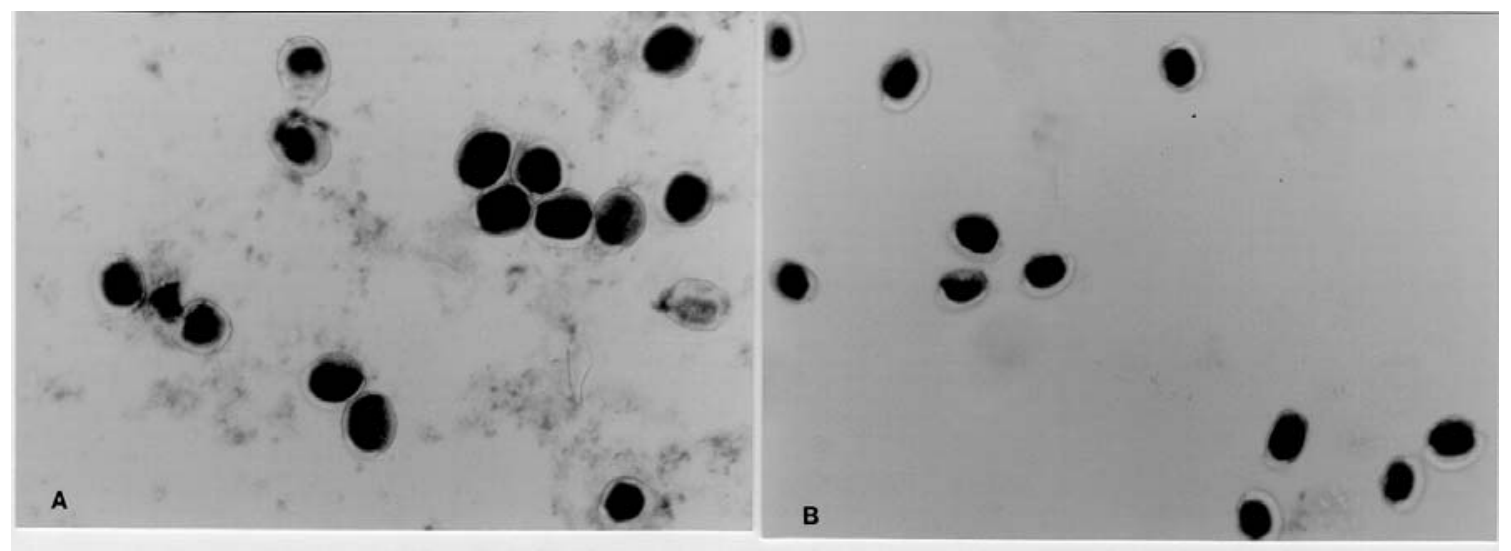

Figura 2. Aspecto geral do pólen in vivo viável (corado) em dois estádios: a) botão floral (142x) e b) flor recém-aberta (142x) de açaizeiros da coleção de germoplasma da Embrapa Amazônia Oriental, Belém-PA, 1998.

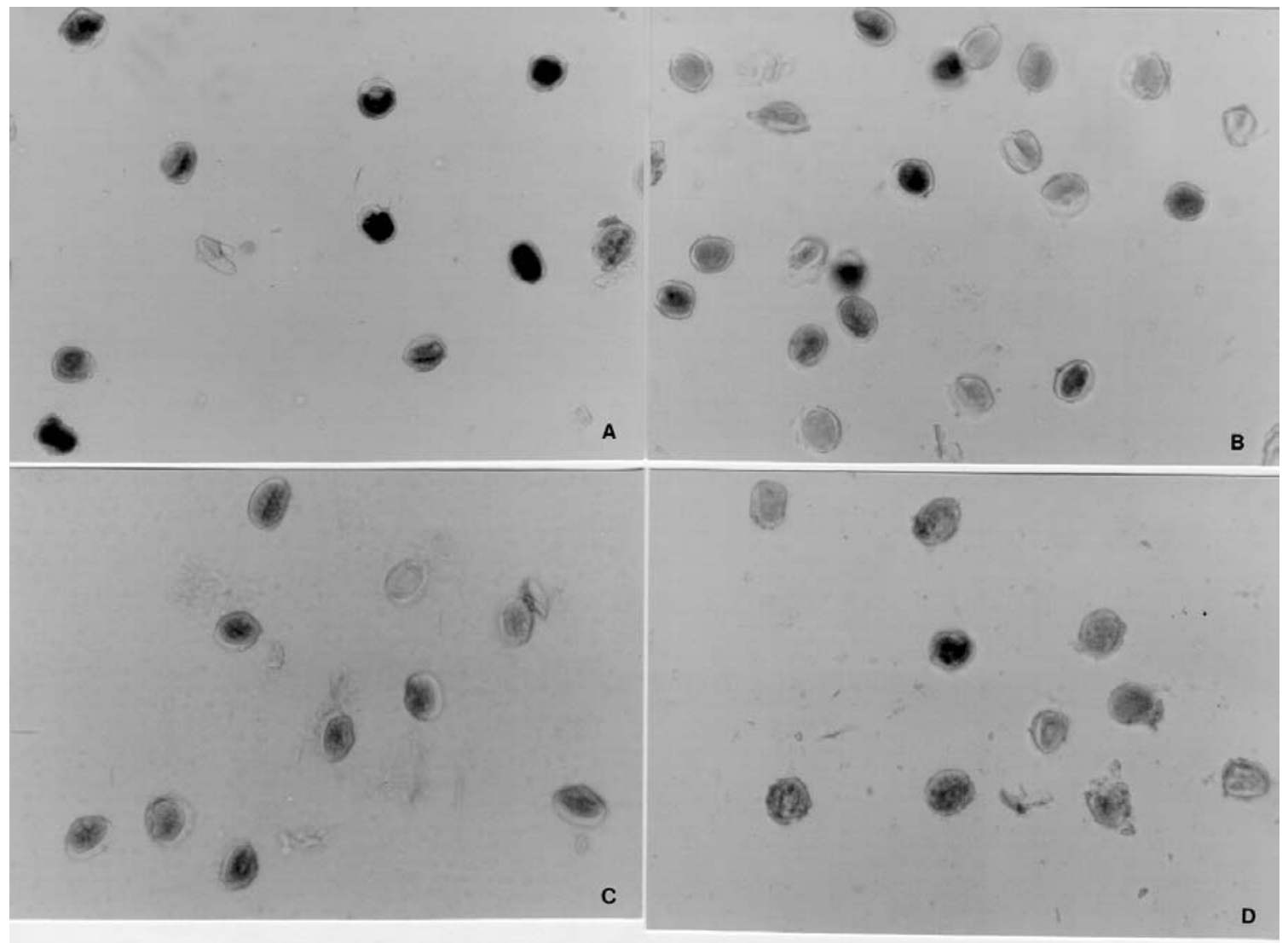

Figura 3. Aspecto geral do pólen in vitro viável (corado) em quatro períodos de armazenamento em freezer: a) um (142x), b) três $(142 x)$, c) seis $(142 x)$ e d) doze meses (142x), de açaizeiros da coleção de germoplasma da Embrapa Amazônia Oriental, Belém-PA, 1998 
polinizações controladas.

É importante enfatizar que a diminuição na percentagem de pólen viáveis encontrada neste trabalho pode está relacionada com vários fatores, tais como: as condições de armazenamento, o recipiente usado no acondicionamento do pólen e a manipulação dos recipientes. Em várias palmeiras a viabilidade do pólen armazenado é mantida se os grãos de pólen obtidos estiverem secos (Bérnard \& Noiret 1970; Rognon \& Nucé de Lamonthe 1978; Miranda 1986) e conservados em baixas temperaturas (Rognon \& Nucé de Lamonthe 1973; Akihama et al. 1979 e Miranda 1986). Contudo, os coeficientes de variações obtidos para os períodos avaliados foram baixos, levando a crer que fatores externos tenham exercido pouca influência.

Analisando os genótipos verifica-se que para o armazenamento de um mês, a melhor viabilidade ocorreu no genótipo 3 (90,2\%) com o indivíduo 5 apresentando o menor valor $(69,1 \%)$. Os mesmos genótipos apresentaram comportamentos semelhantes para três e seis meses de conservação, onde o genótipo 3 continuou se destacando com 88,0 e $85,6 \%$ e o genótipo 5 mostrando os menores valores (Tab. 2). Já no último período, os genótipos 9 e 20 exibiram o melhor e o pior resultado, respectivamente. Os resultados demonstram que apesar dos genótipos terem exibido taxas de viabilidades variáveis, no último período de armazenagem, a maioria deles (dezoito genótipos) alcançou valores acima de 50\%, podendo-se destacar o genótipo 9 com $74,5 \%$. Por outro lado, os genótipos 5 e 20 tiveram valores menores que $50 \%$, atingindo $49,4 \%$ e $48,9 \%$, respectivamente. Com base nas informações apresentadas por Miranda (1993), pode-se considerar que os resultados obtidos para pólen in vitro possam subsidiar programas de melhoramento com o açaizeiro, viabilizando cruzamentos entre indivíduos com potencial econômico que apresentem barreiras temporais de floração, baixa taxa de polinização natural ou geograficamente separados.

\section{Conclusões}

Os resultados obtidos, nas condições do estudo, permitem concluir que:

- Grãos de pólen in vivo de açaizeiro, retirados de botões florais e flores recém-abertas, apresentam viabilidade alta, sendo maior no segundo estádio. Enquanto, grãos de pólen in vitro possuem redução na viabilidade com o aumento do tempo de armazenamento;

- Para pólen in vivo, a maior viabilidade ocorreu no genótipo 19, nos dois estádios avaliados; - Para pólen in vitro, os genótipos 3 e 9 alcançaram os melhores resultados, com as menores reduções de viabilidade nos quatro períodos de armazenamento;

- Com exceção dos genótipos 5 e 20, os demais podem ser utilizados em polinizações controladas sem prejuízos na fecundação em até doze meses de conservação nas condições testadas.

\section{Referências bibliográficas}

Akihama, T.; Omura, M. \& Kosaki, I. 1979. Long-term of fruit tree pollen and its application in breeding. Tropical Agriculture Research 13(4): 238-241.

Arnaud, F. 1979. La pollinisation assistée les plantations de palmier à huile. Récolte et conditionnement du pollen. Oléagineux, Paris: v. 34 , n. 4 , p. 175-176.

Arnaud, F. 1980. Fertilité pollinique de l'hybride Elaeis melanococca x E. guineensis et des espèces parentales. Oléagineux, Paris: v. 35 , n. 3, p. 121 127.

Bernard, G. \& Noiret, J. M. 1970. Le pollen de palmier à huile réclote. Préparation, conditionnement et utilisation pour la fécondation artificielle. Oléagineux, Paris: v. 25, n. 2, p. 67-73.

Bovi, M. L. A; Godoy Junior, G. \& Saes, L. A. 1988. Pesquisas com os gêneros Euterpe e Bactris no Instituto Agronômico da Campinas. Pp. 1-43. In: Eencontro Nacional de Pesquisadores em Palmito, 1, Curitiba, PR, 1987. Anais..., Curitiba, PR. EMBRAPA - CNPF. Documentos, 19.

Cavalcante, P. B. 1991. Frutas comestíveis da Amazônia. $5^{\text {a }}$ ed. Belém: CNPq, p. 25-28 (Coleção Adolfo Ducke). 
Dafni, A. 1992. Pollination ecology: a practical approach (the practical approach series). New York, Oxford: University press. 250p.

Ekaratne, S. N. R \& Senathirajah, S. 1983. Viability and storage of pollen of the oil palm Elaeis guineensis Jacq. Ann. Bot., Paris: n. 51, p. 661 668, 1983.

Kearns, C. A. \& Inouye, D. 1993. Techniques for pollinations biologists. Niwot, Colorado: University press of Colorado. 579p.

Miranda, I. P. A. 1986. Morfologia e aspectos práticos de germinação e do armazenamento do pólen de pupunha Bactris gasipaes H.B.K (Arecaceae). Dissertação de Mestrado. PPG INPA/ FUA, Manaus, 85p.

Miranda, I. P. A. 1993. A importância da conservação in vitro do pólen da pupunheira (Bactris gasipaes Kunth) Arecaceae para o melhoramento genético. Pp. 361-171. In: Ferreira, E. J. G; Santos, G. M.; Leão, E. L. M. \& Oliveira, L. A. (Eds.). Bases científicas para estratégias de preservação e desenvolvimento da Amazônia. v. 2, SCT/INPA, Manaus.
Rognon, F. \& Nuce de Lamonthe, M. 1973. Action du froid sur la conservation du pollen de cocotier. Oléagineux, Paris, v. 28, n. 12, p. 565-566.

Rognon, F. \& Nuce de Lamonthe, M. 1978. Récolte et conditionnement du pollen pour la pollinisation des champs semenciers de cocotiers. Oléagineux, $\mathrm{Pa}-$ ris, v. 33, n. 1, p. 17-21.

Whitehead, R. A. 1966. Progés dans la lyophilisation du pollen de cocotier. Oléagineux, Paris, v. 21, n. 5, p. 281-284. 